\title{
HYPERURICEMIC EFFECTS OF CHOLINERGIC AGENTS IN RATS
}

\author{
Kazumi IWAKI and Yukio YONETANI \\ Shionogi Research Laboratories, Shionogi \& Co., Ltd. \\ Fukushima-ku. Osaka 553, Japan
}

Accepted December 23, 1981

\begin{abstract}
The hyperuricemic effect of cholinergic agents was studied in rats given potassium oxonate which inhibits urate oxidase and in functionally hepatectomized rats. Acetylcholine slightly increased plasma uric acid in the oxonate-treated animals, and the effect was markedly enhanced by pretreatment with physostigmine. Carbachol alone showed the hyperuricemic effect at a smaller dose than acetylcholine. The hyperuricemic effects of physostigmine plus acetylcholine and carbachol alone were also observed in eviscerated rats with nonfunctioning livers. Nephrectomy markedly potentiated cholinergic agent-induced hyperuricemia, and methylatropine but not hexamethonium apparently abolished the induction of hyperuricemia both in potassium oxonate-treated rats and in eviscerated rats with nonfunctioning livers and without kidneys. However, carbacholinduced hyperuricemia was not found in rats given allopurinol whose plasma levels of uric acid were maintained by exogenously administered uric acid. These results supported the ideas that the hyperuricemic effect of cholinergic agents is due to the stimulated production of uric acid and that uric acid production in tissues other than the liver and the gastrointestinal viscera is closely related to the induction mechanisms of hyperuricemia.
\end{abstract}

We recently reported a hyperuricemic effect of catecholamine in rats $(1,2)$. Demartini (3) and Sumi and Umeda (4) also showed the participation of catecholamine in the induction of hyperuricemia. On the other hand, a role of the parasympathetic nervous system in hyperuricemia was suggested by Postlethwaite et al. (5) which was based on the increased clearance of uric acid in hyperuricemic subjects given anticholinergic agents. These facts indicate that the autonomic nervous system participates in the pathogenesis of hyperuricemia, but there has been no direct evidence to show the hyperuricemic and/or hypouricosuric effect of cholinergic agents. Accordingly, the effect of cholinergic agents on uric acid metabolism was studied using rats in this report, and cholinergic agents were found to produce an obvious hyperuricemia by stimulating uric acid production.

\section{MATERIALS AND METHODS}

Animals and treatments: Eight-week-old male Wistar strain rats were used. In order to inhibit the metabolism of uric acid to allantoin. potassium oxonate was administered i.p. at the dose of $250 \mathrm{mg} / \mathrm{kg}$ according to Johnson et al. (6).

Two different operations were carried out to produce functionally hepatectomized animals under anesthesia with sodium pentobarbital (50 mg/kg i.p.). One type was done to stop the blood supply to the liver by 
ligating the portal vein and the hepatic artery and circulating the portal vein blood into the femoral vein by means of a peristaltic pump (Tokyo Rikakikai Co.) at a flow rate of $3.0 \mathrm{ml} /$ min. The operated animals were used as rats with functional hepatectomy. The other type of operation was performed to produce eviscerated rats with nonfunctioning livers basically according to the method of Penhos et al. (7). The coeliac artery, the superior mesenteric artery, the bile duct. the portal vein, the rectum and the esophagus were ligated and cut off in this order, resulting in functional hepatectomy. Next. the stomach. small and large intestines, mesentery, spleen and pancreas were removed. These animals were used as eviscerated rats with nonfunctioning livers. Nephrectomy was performed simultaneously, if necessary. A tracheal cannula was inserted into the operated animals, then $5 \mathrm{ml} / \mathrm{kg}$ of $5 \%$ glucose solution was administered s.c. every hour.

Blood was collected from conscious rats by decapitation and from anesthetized ones from the right jugular vein. Urine was collected using individual metabolism cages. Methods for drug administration are described in the footnotes of the figures and tables, and the animals of the control group were given saline instead of agents.

Determination of uric acid: Blood samples were immediately cooled in an ice bath after collection, and the plasma was separated as soon as possible. The uric acid content in plasma and urine was determined as described previously (8)

Chemicals: Drugs used were acetylcholine chloride (Sigma), physostigmine sulfate (Merck), carbachal (Sigma), atropine methyinitrate (Tokyo Kasei), hexamethonium bromide (Sigma), potassium oxonate (Calbiochen1), allopurinol (Sigma), and uric acid (Tokyo Kasei). Potassium oxonate and allopurinol were suspended in $1 \%$ gum arabic solution. Uric acid was also suspended in gum arabic solution when administered i.p. but dissolved in a sodium hydroxide solution. diluted with saline, then neutralized with hydrochloric acid just before use when administered s.c. Other drugs were dissolved in saline, and all drugs were usually administered in a volume of $2 \mathrm{ml} / \mathrm{kg}$.

\section{RESULTS}

Effects of cholinergic agents on plasma uric acid: First, the effect of cholinergic agents on plasma uric acid level was studied using potassium oxonate-treated rats. Figure 1 shows the progressive change of plasma uric acid due to intraperitoneally administered acetyicholine or carbachol. Acetylcholine slightly increased plasma uric acid. while a smaller dose of carbachol produced a more apparent increase.

As shown in Table 1, the increase of plasma uric acid due to acetylcholine or carbachol depended upon their doses. The

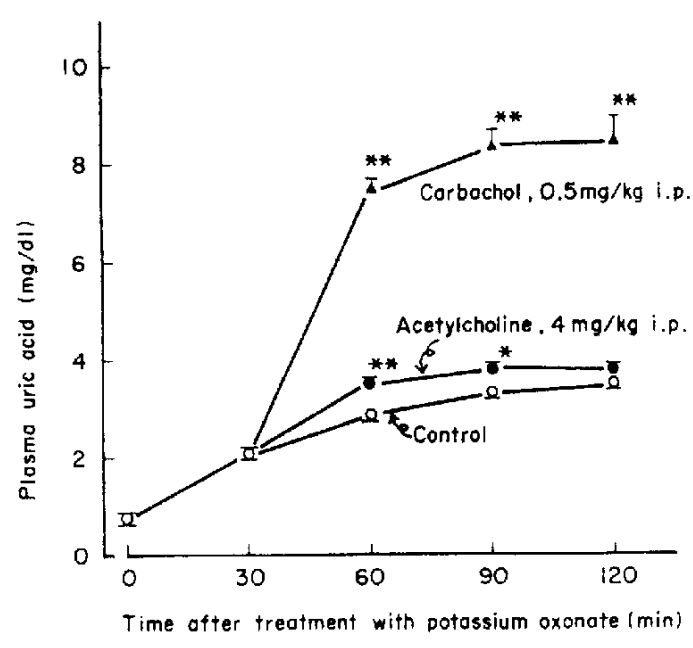

Fig. 1. Effects of cholinergic agents on plasma uric acid in potassium oxonate-treated rats. Potassium oxonate $(250 \mathrm{mg} / \mathrm{kg}$, i.p.) was initially given, then acetylcholine or carbachol was administered $30 \mathrm{~min}$ later. Animals were sacrificed by decapitation at the indicated time. Values are the mean \pm S.E. of seven animals. " $\cdots$ : Significantly different from the control group at $P<0.05$ and 0.01 , respectively. 
Table 1. Dose dependent increase of plasma uric acid in the administration of cholinergic agents to potassium oxonate-treated rats

\begin{tabular}{lcc}
\hline Treatment & Dose $(\mathrm{mg} / \mathrm{kg} \mathrm{i.p.)}$ & Plasma uric acid $(\mathrm{mg} / \mathrm{dl})$ \\
\hline Control & & $-92 \pm 0.09(6)$ \\
Acetylcholine & 2.0 & $3.62 \pm 0.21(5)^{*}$ \\
& 4.0 & $3.79 \pm 0.24(5)^{* *}$ \\
& 8.0 & $4.80 \pm 0.27(6)^{* *}$ \\
Physostigmine & 0.15 & $3.29 \pm 0.10(6)^{*}$ \\
Physostigmine+Acetylcholine & $0.15+2.0$ & $6.27 \pm 0.28(6)^{\dagger+}$ \\
& $0.15+4.0$ & $6.50 \pm 0.24(5)^{\dagger \dagger}$ \\
Control & $0.15+8.0$ & $8.01 \pm 0.51(5)^{\dagger \dagger}$ \\
Carbachol & & $3.24 \pm 0.28(6)$ \\
& 0.1 & $5.60 \pm 0.30(7)^{* *}$ \\
& 0.25 & $6.17 \pm 0.31(7)^{* *}$ \\
& 0.5 & $7.77 \pm 0.46(7)^{* *}$ \\
\hline
\end{tabular}

Acetylcholine and carbachol were given $30 \mathrm{~min}$ after the administration of potassium oxonate $(250 \mathrm{mg} / \mathrm{kg}$ i.p.). Acetylcholine-treated rats and carbachol-treated ones were sacrificed by decapitation 30 and 60 min later, respectively. Physostigmine was administered 5 min before the acetylcholine. Data represent the mean \pm S.E. and the number of animals is given in parentheses. "**: Significantly different from the control group at $P<0.05$ and 0.01 , respectively. $t^{+}$: Significantly different from the group given physostigmine alone at $P<0.01$.

hyperuricemic effect of acetylcholine was markedly potentiated by pretreatment with physostigmine, although the hyperuricemic effect of physostigmine alone was slight.

Carbachol-induced hyperuricemia was also observed in functionally hepatectomized rats. Figure 2 shows the increase of plasma uric acid in eviscerated rats with nonfunctioning livers after their operations and the effect of subcutaneously administered carbachol 10.2 $\mathrm{mg} / \mathrm{kg}$ ) to the operated animals.

The increases of plasma uric acid elicited by subcutaneously administered carbachol $(0.2 \mathrm{mg} / \mathrm{kg})$ under anesthesia with sodium pentobarbital were compared among three groups of animals: potassium oxonate-treated rats, rats with functional hepatectomy, and eviscerated rats with nonfunctioning livers (Fig. 3). In the experiments, the increments of plasma uric acid due to the treatment with potassium oxonate or the operation for

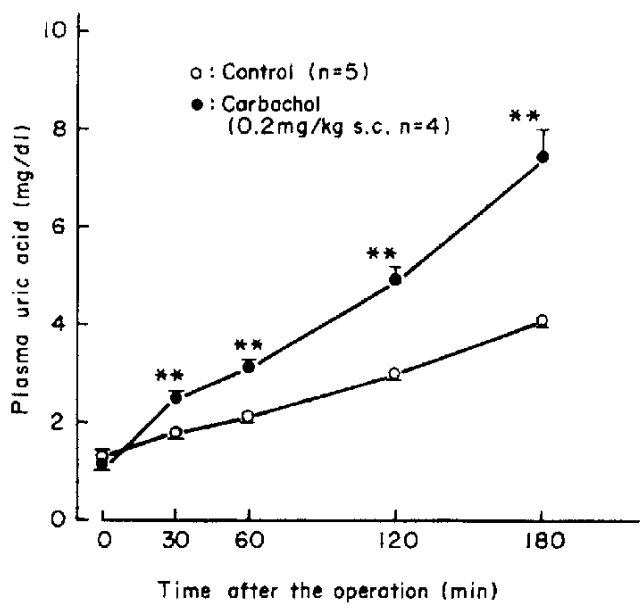

Fig. 2. Increase of plasma uric acid in eviscerated rats with nonfunctioning livers and the effect of carbachol on the plasma uric acid level. Carbachol was administered immediately after the operation. Values are the meants.E. **: Significantly different from the control group at $\mathrm{P}<0.01$ 


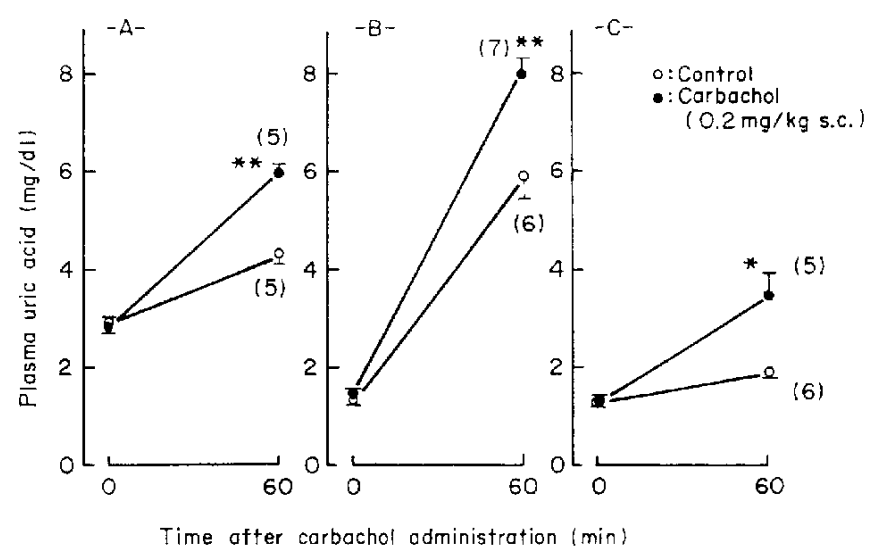

Fig. 3. Effect of carbachol on plasma uric acid in potassium oxonate-treated rats ( $A$ ), in rats with functional hepatectomy $(B)$. and in eviscerated rats with nonfunctioning livers (C). --A-: Potassium oxonate $(250 \mathrm{mg} / \mathrm{kg}$ i.p.) was given $20 \mathrm{~min}$ before the administration of sodium pentobarbital $(50 \mathrm{mg} / \mathrm{kg}$ i.p. $)$. After the anesthesia, a tracheal cannula was inserted, then carbachol was administered $30 \mathrm{~min}$ after the treatment with potassium oxonate. - B - and - C-: Carbachol was administered immediately after the operation for producing functional hepatectomy. Values are the mean \pm S.E. and the number of animals is given in parentheses. " ${ }^{* *}$ : Significantly different from the control group at $P<0.05$ and 0.01 , respectively.

Table 2. Effect of carbachol on plasma and urinary uric acid in rats treated with potassium oxonate, allopurinol, and uric acid

\begin{tabular}{ccccc}
\hline $\begin{array}{c}\text { Carbachol } \\
\text { (mg/kg i.p. })\end{array}$ & $n$ & $\begin{array}{c}\text { Urine volume } \\
(\mathrm{ml})\end{array}$ & $\begin{array}{c}\text { Urine-excreted } \\
\text { uric acid }(\mathrm{mg})\end{array}$ & $\begin{array}{c}\text { Plasma uric } \\
\text { acid }(\mathrm{mg} / \mathrm{dl})\end{array}$ \\
\hline 0 & 4 & $0.6 \pm 0.2$ & $1.3 \pm 0.4$ & $5.00 \pm 0.64$ \\
0.1 & 7 & $0.7 \pm 0.1$ & $1.4 \pm 0.2$ & $5.65 \pm 0.20$ \\
0.25 & 5 & $2.1 \pm 0.3^{* *}$ & $1.2 \pm 0.4$ & $5.53 \pm 0.44$ \\
0.5 & 7 & $4.1 \pm 0.2^{* *}$ & $0.8 \pm 0.1$ & $5.45 \pm 0.36$ \\
\hline
\end{tabular}

Potassium oxonate $(250 \mathrm{mg} / \mathrm{kg}$ i.p. $)$ and allopurinol $(100 \mathrm{mg} / \mathrm{kg}$ p.o.) were initially administered, then uric acid (25 mg/kg i.p.) and carbachol were given $30 \mathrm{~min}$ later. Urine was collected for $1.5 \mathrm{hr}$ after the administration of carbachol. then the animals were sacrificed by decapitation. Data represent the mean \pm S.E. **: Significantly different from the control group at $P<0.01$.

producing functional hepatectomy were different, but the increments elicited by the carbachol treatment for the three groups were similar.

Effect of renal function on cholinergic agent-induced hyperuricemia: In order to determine whether the hyperuricemic effect of cholinergic agents was due to their actions on renal excretion of uric acid, the effect of carbachol was studied using rats given potassium oxonate, allopurinol and uric acid. As shown in Table 2, carbachol had no effect on either the plasma level or the urineexcreted amount of uric acid in the animals, although the agent produced an obvious increase of urine volume.

The plasma uric acid level in eviscerated rats with nonfunctioning livers given allopurinol and uric acid was also unaffected by carbachol (Table 3 ). 
Table 3. Effect of carbachol on plasma uric acid in eviscerated rats with nonfunctioning livers under the treatment with allopurinol and uric acid

\begin{tabular}{cc}
$\begin{array}{c}\text { Carbachol } \\
(\mathrm{mg} / \mathrm{kg} \mathrm{s.c.})\end{array}$ & $\begin{array}{c}\text { Increment of plasma uric acid } \\
(\mathrm{mg} / \mathrm{dl})\end{array}$ \\
0 & $2.63 \pm 0.16$ \\
0.05 & $2.28 \pm 0.05$ \\
0.2 & $2.87 \pm 0.26$ \\
\hline
\end{tabular}

Allopurinol $(100 \mathrm{mg} / \mathrm{kg}$ p.o.) was given one hour prior to the operation, then uric acid $(20 \mathrm{mg} / \mathrm{kg} \mathrm{s.c.})$ and carbachol were administered immediately after the operation. The increment of plasma uric acid during the first hour after the administration of carbachol was assessed. Data represent the mean \pm S.E. of six animals.

Table 4. Effect of nephrectomy on plasma uric acid levels elicited by cholinergic agents in eviscerated rats with nonfunctioning livers

\begin{tabular}{|c|c|c|c|}
\hline \multirow[b]{2}{*}{ Treatment } & \multirow{2}{*}{$\begin{array}{c}\text { Dose } \\
(\mathrm{mg} / \mathrm{kg} \text { s.c. })\end{array}$} & \multicolumn{2}{|c|}{ Increment of plasma uric acid (mg/dl) } \\
\hline & & $\begin{array}{l}\text { Without } \\
\text { nephrectomy }\end{array}$ & $\begin{array}{c}\text { With } \\
\text { nephrectomy }\end{array}$ \\
\hline \multicolumn{4}{|l|}{$-\mathrm{A}-$} \\
\hline Control & & $0.75 \pm 0.07$ & $1.63 \pm 0.15$ \\
\hline Acetylcholine & 1.0 & $0.87 \pm 0.04(7)$ & $1.64 \pm 0.07$ \\
\hline Physostigmine & 0.15 & $0.98 \pm 0.08(7)^{*}$ & $3.23 \pm 0.32(6)^{* *}$ \\
\hline $\begin{array}{l}\text { Physostigmine } \\
\text { +Acetylcholine }\end{array}$ & 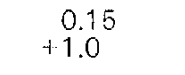 & $1.23 \pm 0.13(7)^{* *}$ & $5.85 \pm 0.39(7)^{* *}$ \\
\hline \multicolumn{4}{|l|}{$-B-$} \\
\hline \multirow[t]{2}{*}{ Control } & & $0.66 \pm 0.11$ & $1.68 \pm 0.07(6)$ \\
\hline & 0.02 & $0.64 \pm 0.05$ & $3.58 \pm 0.21(5)^{* *}$ \\
\hline \multirow[t]{3}{*}{ Carbachol } & 0.05 & $0.99 \pm 0.11(5)^{*}$ & $6.08 \pm 0.66(7)^{* *}$ \\
\hline & 0.7 & $1.47 \pm 0.25(4)^{*}$ & $6.47 \pm 0.36(7)^{* *}$ \\
\hline & 0.2 & $3.00 \pm 0.46(5)^{* *}$ & $6.64 \pm 0.54(7)^{* *}$ \\
\hline
\end{tabular}

-A--: Physostigmine was administered immediately after the operation, then acetylcholine was given 5 min later. - B - Carbachol was administered immediately after the operation. The increment of plasma uric acid during the first hour after the operation was assessed. Data represent the mean $\pm 5 . E$. and the number of animals is given in parentheses. " ${ }^{* *}$ : Sig. nificantly different from the control group at $P<0.05$ and 0.01 , respectively.

Table 4 shows the effect of nephrectomy on plasma uric acid levels elicited by cholinergic agents in eviscerated rats with nonfunctioning livers. Acetylcholine alone did not cause hyperuricemia in the animals, but the hyperuricemia induced by physostigmine, physostigmine plus acetylcholine. and carbachol was markedly potentiated by nephrectomy. Nephrectomy also led to a higher level of plasma uric acid when the level was maintained by exogenously administered uric acid. However, the potentiated level was only 1.5-fold of the plasma uric acid level without nephrectomy, and it was much less than that in carbachol-induced hyperuricemia.

Effects of anticholinergic agents on carbachol-induced hyperuricemia: The effects of methylatropine and hexamethonium on carbachol-induced hyperuricemia were studied with potassium oxonate-treated rats and eviscerated rats with nonfunctioning livers and without kidneys. Methylatropine 
Table 5. Effects of methylatropine and hexamethonium on carbachol-induced hyperuricemia in potassium oxonate-treated rats (A) and in eviscerated rats with nonfunctioning livers and without kidneys (B)

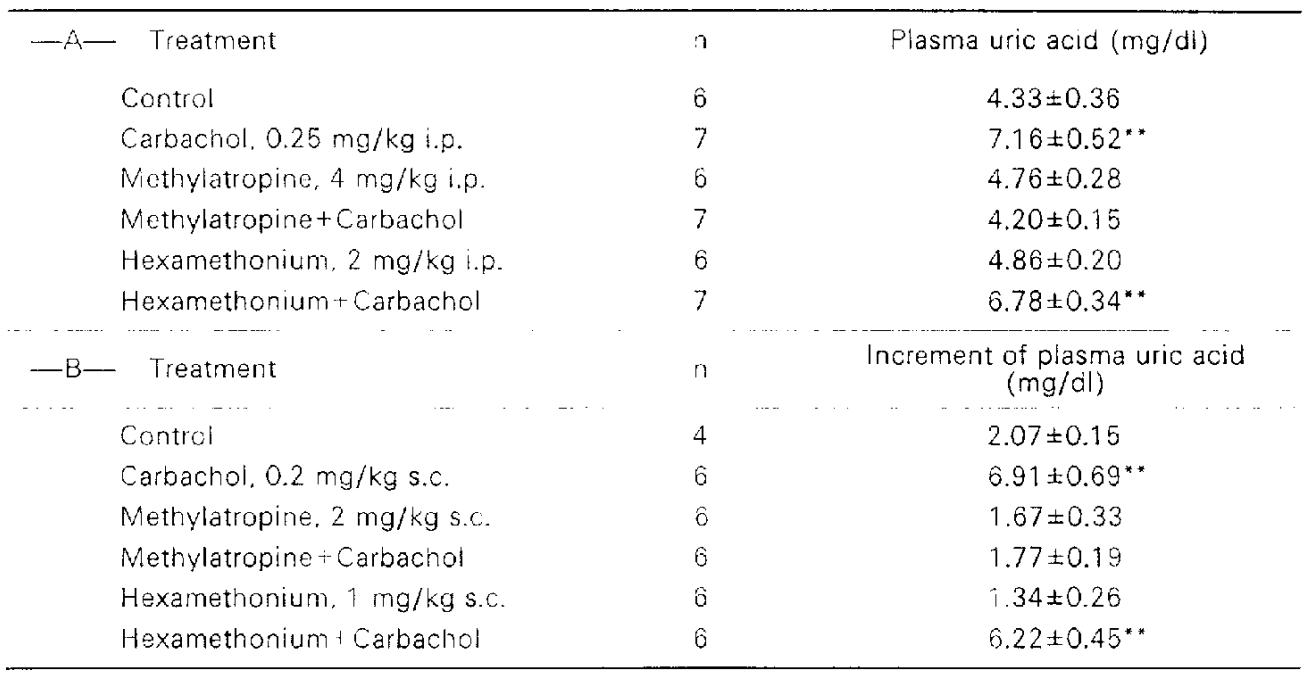

_-A - Potassium oxonate $(250 \mathrm{mg} / \mathrm{kg}$ i.p.) was initially given, then carbachol was admir.istered $1 \mathrm{hr}$ later. Methylatropine and hexamethonium were administered 30 and $5 \mathrm{~min}$ beforo the carbachol. respectively. Animals were sacificed by decapitation 1 hr after the administration of carbachol. - $B-$ : All agents vere administered immediately after the operation, and the increment of plasma uric acid during the first hour after the operation was assessed. Data represent the meantS.E. **: Significantly different from the control group at $P<0.01$.

completely blocked the hyperuricemia in both animals. while hexamethonium had no effect (Table 5).

\section{DISCUSSION}

The present study investigated the hyperuricemic effect of cholinergic agents using rats given potassium oxonate which is an inhibitor of urate oxidase, rats with functional hepatectomy, and eviscerated rats with nonfunctioning livers. As indicated in Tables 2 and 3 , no hyperuricemia was caused by carbachol in the animals given allopurinol and uric acid. These animals were useful for assessing drug effects on renal excretion of uric acid because uric acid production was inhibited by allopurinol and the plasma uric acid could be exogenously supplied (8). Thus, the results indicated that the hyperuricemic effect of carbachol is independent of the renal effect on uric acid excretion.

In addition. nephrectomy markedly enhanced the hyperuricemic effect of cholinergic agents. The enhancement was observed not only in eviscerated rats with nonfunctioning livers but also in potassium oxonate-treated animals. Although this effect of nephrectomy was also studied with eviscerated rats with nonfunctioning livers given isoproterenol, of which the hyperuricemic effect was shown in our previous report (2), the plasma uric acid level elicited here was the same as that produced by exogenously administered uric acid. Lüthi and Waser (9) reported that carbachol concentration was highest in the kidney when it was administered to atropinized cats. Thus, the markedly enhanced hyperuricemia produced by carbachol or physostigmine plus acetylcholine in nephrectomized rats may 
occur because the agents are mainly disposed by the renal function.

Carbachol-induced hyperuricemia in potassium oxonate-treated rats and eviscerated rats with nonfunctioning livers and without kidneys was blocked completely by pretreatment with methylatropine but not with hexamethonium. Yamamoto et a!. (10) reported that the hepatic 5-phosphoribosyl-1pyrophosphate concentration in mice is increased by acetylcholine or carbachol, and this effect is inhibited by atropine but not affected by hexamethonium. Thus, though the question remains as to the renal contribution to the induction of hyperuricemia, the present study supports stimulated production of uric acid as the cause of cholinergic agentinduced hyperuricemia, and the enhanced production of uric acid may be classified as a muscarinic action of cholinergic agents.

Another question involves the significance of uric acid production in tissues other than the liver and the gastrointestinal viscera in cholinergic agent-induced hyperuricemia, like that induced by catecholamine which was described previously (2). Generally. most uric acid is thought to be produced in the liver and the intestines in the normal state (11). However, as shown in our studies, hyperuricemia could be easily induced in functionally hepatectomized animals with evisceration when they received catecholamine or cholinergic agents. In addition. the hyperuricemic state in such animals was appreciable compared with that in potassium oxonate-treated rats. Therefore, the uric acid production system in tissues other than the liver and the gastrointestinal viscera must be important in the induction of hyper- uricemia due to the disturbance of neurotransmitters.

\section{REFERENCES}

1) Yonetani, $Y .$, Ishii, $M$. and Ogawa, $Y .:$ Stimulation by catecholamine of purine catabolism in rats and chickens. Japan. J. Pharmacol. 29, 211-221 (1979)

2) Yonetani, $Y$. and Iwaki, K.: Catecholamineinduced hyperuricemia in eviscerated rats with functional hepatectomy. Japan. J. Pharmacol. 31, 323-332 (1981)

3) Demartini, F.E.: Hyperuricemia induced by drugs. Arth. Rheum. 8, 823-829 (1965)

4) Sumi, T. and Umeda, $Y$.: Adrenal epinephrine in hyperuricemia induced by hypothalamic stimulation of the rat. Am, J. Physiol. 236, E212-E215 (1979)

5) Postlethwaite, A.E., Ramsdell, C.M. and Kelly, W.N.: Uricosuric effect of an anticholinergic agent in hyperuricemic subjects. Archs int. Med. 134, 270-275 (1974)

6) Johnson, W.J., Stavric, B. and Chartrand, A.: Uricase inhibition in the rat by s-triazines: an animal model for hyperuricemia and hyperuricosuria. Proc. Soc. exp. Biol. Med. 131, 8-12 (1969)

7) Penhos, J.C., Woodbury, C., Tizabi, Y. and Ramey, E.R.: Metabolic studies in eviscerated rats with functional livers. Proc. Soc. exp. Biol. Med. 148, 1159-1163 (1975)

8) Yonetani, Y., Ishii, M. and Iwaki, K.: Hyperuricemia induced by some antihypertensives and uricosuric drugs in oxonate-treated rats. Japan. J. Pharmacol. 30, 829-840 (1980)

9) Lüthi, U. and Waser, P.G.: Verteilung und Metabolismus von ${ }^{14} \mathrm{C}$-Carbachol bei Atropinisierten Katzen. Archs int. Pharmacodyn. Thér. 167, 369-402 (1967)

10) Yamamoto, I., Mizui, T., Noguchi, Y. and Iwata, H.: Effects of catecholamines, acetylcholine and cyclic nucleotides on 5-phosphoribosyl-1-pyrophosphate levels in mouse liver. Uric Acid Research 2, 1-11 (1978)

11) Fox, I.H.: Degradation of purine nucleotides. Handb. Exp. Pharm. 51, 93-124 (1978) 